\title{
The role of adiponectin in the production of IL-6, IL-8, VEGF and MMPs in human endothelial cells and osteoblasts: implications for arthritic joints
}

\author{
Yeon-Ah Lee ${ }^{1,2,3}$, Hye-In Ji ${ }^{1,3}$, Sang-Hoon Lee ${ }^{2}$, Seung-Jae Hong ${ }^{2}$, Hyung-In Yang ${ }^{2}$, \\ Myung Chul Yoo ${ }^{1}$ and Kyoung Soo Kim ${ }^{1}$
}

This study was performed to evaluate the contribution of adiponectin to the production of interleukin (IL)-6, IL-8, vascular endothelial growth factor (VEGF), matrix metalloproteinase (MMP)-1 and MMP-13 in human endothelial cells and osteoblasts in arthritic joints. Cultured human umbilical vascular endothelial cells (HUVECs) and osteoblasts were stimulated with adiponectin

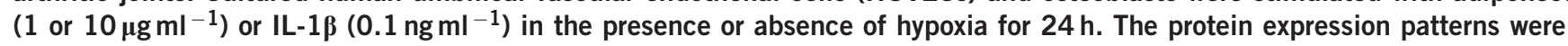
examined by analyzing culture supernatants using the enzyme-linked immunosorbent assay (ELISA). Adiponectin significantly stimulated the production of VEGF, MMP-1 and MMP-13 in osteoblasts but not in endothelial cells, whereas it significantly stimulated the production of IL- 6 and IL- 8 in both endothelial cells and osteoblasts. The increase in VEGF production induced by adiponectin was significantly greater than that induced by IL-1ß. The production of IL-6 and IL-8 in adiponectin-stimulated endothelial cells was approximately 10 -fold higher than that in IL-1 $\beta$-stimulated endothelial cells; in osteoblasts, adiponectininduced IL- 6 and IL-8 secretion was approximately twofold higher than that induced by IL-1ß. In addition, IL-8 production in endothelial cells was approximately sevenfold higher than in osteoblasts. However, IL- 6 levels were similar between the two cell types, suggesting that adiponectin may be involved in the production of IL-8 in endothelial cells, which may have an important role in neutrophil recruitment to arthritic joints. Furthermore, the increases in protein expression induced by adiponectin were differentially regulated by hypoxia. In conclusion, adiponectin has a more important role than does IL-1ß in the production of mediators that drive synovitis and joint destruction in endothelial cells and osteoblasts at physiological concentrations.

Experimental \& Molecular Medicine (2014) 46, e72; doi:10.1038/emm.2013.141; published online 17 January 2014

Keywords: adiponectin; cytokines and inflammatory mediators; endothelium; osteoblast; rheumatoid arthritis

\section{INTRODUCTION}

In rheumatoid arthritis (RA), proliferative fibroblast-like synoviocytes (FLSs) have important roles in progressive damage to articular cartilage and subchondral bone and in the propagation of inflammation. These cells produce many mediators of inflammation, such as cytokines and matrix metalloproteinases (MMPs), which contribute to cartilage degradation in the joints. ${ }^{1}$ Thus, FLSs are regarded as key players in joint inflammation. ${ }^{2}$ In addition to FLSs, other cells such as lymphocytes, chondrocytes, osteoblasts and endothelial cells are also partly involved in RA pathophysiology. In particular, the perpetuation of neovascularization in RA is highly necessary for leukocyte extravasation into the synovium and pannus formation, which is required for the persistence of RA. ${ }^{3}$ Numerous soluble and cell surface-bound angiogenic mediators, including growth factors, cytokines, proteases, matrix macromolecules, cell adhesion receptors, chemokines and chemokine receptors, have been implicated in neovascularization. The exposure of osteoblasts in arthritic joints to inflammation also stimulates the production of various inflammatory mediators and MMPs in response to proinflammatory cytokines. ${ }^{4,5}$

Recently, articular adipose tissue has been considered an important contributor to the pathological process taking place

\footnotetext{
${ }^{1}$ East-West Bone and Joint Research Institute, Kyung Hee University Hospital, Kyung Hee University, Seoul, Republic of Korea and ${ }^{2}$ Division of Rheumatology, Department of Internal Medicine, Kyung Hee University Medical School, Seoul, Republic of Korea

${ }^{3}$ These authors equally contributed to this work.

Correspondence: Professor KS Kim, East-West Bone and Joint Research Institute, Kyung Hee University Hospital at Gangdong, Kyung Hee University, 149 Sangil-dong, Gangdong-gu, Seoul 134-727, Republic of Korea.

E-mail: labrea46@naver.com
}

Received 6 August 2013; revised 29 September 2013; accepted 7 October 2013 
in the RA joint because the major cell type of adipose tissue, the adipocyte, produces cytokine-like mediators called adipokines. ${ }^{6}$ Among the adipokines, adiponectin appears to have an important role in the pathogenesis of RA. The levels of adiponectin in synovial fluid and serum are elevated in patients with RA. ${ }^{7,8}$ Adiponectin also induces the production of the proinflammatory cytokines interleukin (IL)-6, MMP-1 and IL-8 by RA synovial fibroblasts in vitro. ${ }^{9,10}$ We recently suggested that adiponectin may contribute to synovitis and joint destruction in RA by stimulating the greater vascular endothelial growth factor (VEGF), MMP-1 and MMP-13 expression in FLSs than do proinflammatory mediators. ${ }^{11}$ It has been shown that adiponectin stimulates the production of VEGF, MMP-1 and MMP-13 at the same levels as IL-1 $\beta$ at their physiological concentrations, although adiponectin induces much lower levels of IL-6, IL-8 and $\mathrm{PGE}_{2}$ than does stimulation by IL-1 $\beta$. Meanwhile, Gomez et al. ${ }^{12,13}$ showed that adiponectin induced nitric oxide synthase type II, IL-6, IL-8, MMP-3, MMP-9 and MCP-1 in cultured chondrocytes. They also suggested that adiponectin increased vascular cell adhesion molecule 1 expression, which was responsible for leukocyte and monocyte infiltration into inflamed joints, in chondrocytes, and thus perpetuated cartilage-degrading processes. ${ }^{14}$ More importantly, in a recent report we demonstrated that adiponectin may have synergistic effects in combination with IL-1 $\beta$ on the production of proinflammatory mediators during arthritic joint inflammation. ${ }^{15}$ These findings suggested that adiponectin may be more important in the pathogenesis of RA than previously thought.

Hypoxia is one of the primary characteristics of inflamed joints in RA. ${ }^{16}$ Hypoxic conditions have an important role in rendering synovial fibroblasts pro-angiogenic and proinvasive; thus, hypoxia leads to the debilitating features that are characteristic of RA. ${ }^{17}$ The angiogenic and invasive behaviors of FLSs in RA appear to depend on the cooperative action of VEGF and MMPs, which are stimulated by hypoxia in synovial fibroblasts. ${ }^{18}$ Thus, VEGF and MMPs have been recognized as therapeutic targets for treatments designed to delay RA symptoms. ${ }^{19,20}$ In our previous report, we showed that increased expression of MMP-1 and MMP-13 in response to IL-1 $\beta$ in FLSs was differentially regulated by hypoxic conditions, mimicking conditions in inflamed arthritic joints. ${ }^{21}$

Although endothelial cells and osteoblasts may both have important roles in the pathogenesis and perpetuation of RA, little is known about how endothelial cells and osteoblasts respond to adiponectin or hypoxic conditions to produce MMPs and proinflammatory mediators in arthritic joints. Adiponectin is produced not only by adipose tissue but also by synovial fibroblasts, endothelial cells and osteoblasts. ${ }^{9,22}$ In arthritic joints, adiponectin may affect gene expression in these cells in autocrine and/or paracrine manners. In this study, we evaluated the contribution of adiponectin to the production of IL-6, IL-8, VEGF, MMP-1 and MMP-13 in human endothelial cells and osteoblasts in arthritic joints.

\section{MATERIALS AND METHODS}

\section{Cell culture}

Human umbilical vein endothelial cells (HUVECs) and human osteoblasts were obtained from the Korean Cell Line Bank (KCLB, Seoul, Korea) and Cell Applications, Inc. (San Diego, CA, USA), respectively. Endothelial cells and osteoblasts were cultured in T-75 flasks (NUNC) containing EGM-2 (Lonza, Alpharetta, GA, USA) and osteoblast growth medium (Cell Applications, Inc.), respectively. After the cells had grown to confluence, they were split at a 1:4 ratio. Cell passages 5-6 were used for all experiments. The cells $\left(5 \times 10^{5}\right.$ cells per $60 \mathrm{~mm}$ dish per $2 \mathrm{ml}$ of medium) were cultured overnight and treated in serum-free medium with human recombinant adiponectin ( 1 or $\left.10 \mu \mathrm{g} \mathrm{ml}^{-1}\right)$ or IL-1 $\beta\left(0.1 \mathrm{ng} \mathrm{ml}^{-1}\right)$, which was produced in Escherichia coli (ProSpec, Rehovot, Israel). The cells were preincubated in serum-free medium for $2 \mathrm{~h}$, and cultures were placed in fresh serumfree medium before stimulation with adiponectin or IL-1 $\beta$ under hypoxic or normoxic conditions $\left(5 \% \mathrm{CO}_{2}, 37^{\circ} \mathrm{C}\right)$. Hypoxic conditions were generated by incubating the cells at $2 \% \mathrm{O}_{2}$ in a hypoxic chamber gassed with a combination of $\mathrm{N}_{2}$ and $\mathrm{CO}_{2}$ (Invivo 2 200, Ruskinn Technology Ltd, Pencoed, UK). Conditioned medium was collected after $24 \mathrm{~h}$. Cell cultures were centrifuged, and the supernatants were collected for enzyme-linked immunosorbent assay (ELISA). Three independent experiments using cells from one donor were performed in quadruplicate.

\section{ELISA}

The supernatants were collected and analyzed for VEGF, MMP-1, MMP-13 (R\&D Systems Inc., Minneapolis, MN, USA), IL-6 and IL-8 (BD, San Jose, CA, USA) using three ELISA kits (VEGF, MMP-1 and MMP-13) from R\&D systems. Two kits (IL-6 and IL-8) are from BD Bioscience.

\section{Statistical analysis}

The in vitro experimental data are expressed as the mean \pm s.d. of quadruplicate samples. The expression levels of the factors were compared between groups with the Mann-Whitney test. Prism 5.02 software (GraphPad Software, San Diego, CA, USA) was used for statistical analysis and graphing. Differences were considered significant at $P<0.05$.

\section{RESULTS}

Expression patterns of VEGF, MMP-1 and MMP-13 in human endothelial cells and osteoblasts in response to adiponectin

The expression of VEGF, MMP-1 and MMP-13, which are involved in matrix degradation and neovascularization, was evaluated in endothelial cells and osteoblasts in response to adiponectin. The cells were stimulated for $24 \mathrm{~h}$ with adiponectin ( 1 and $\left.10 \mu \mathrm{g} \mathrm{ml}^{-1}\right)$ or IL-1 $\left(0.1 \mathrm{ng} \mathrm{ml}^{-1}\right)$ as a reference. As shown in Figure 1, adiponectin significantly stimulated the production of VEGF, MMP- 1 and MMP- 13 by osteoblasts but not by endothelial cells. The levels of VEGF and MMPs were significantly increased in osteoblasts, even at a concentration of $1 \mu \mathrm{g} \mathrm{ml}^{-1}$ adiponectin. Furthermore, adiponectin $\left(10 \mu \mathrm{g} \mathrm{ml}^{-1}\right)$ increased the VEGF protein level by twofold in osteoblasts when compared with that in unstimulated osteoblasts (mean \pm s.d., $281.8 \pm 22.9$ vs $145.4 \pm$ $18.9 \mathrm{pg} \mathrm{ml}^{-1}$ ). The increase in VEGF protein induced by adiponectin was significantly greater than that induced by 
a
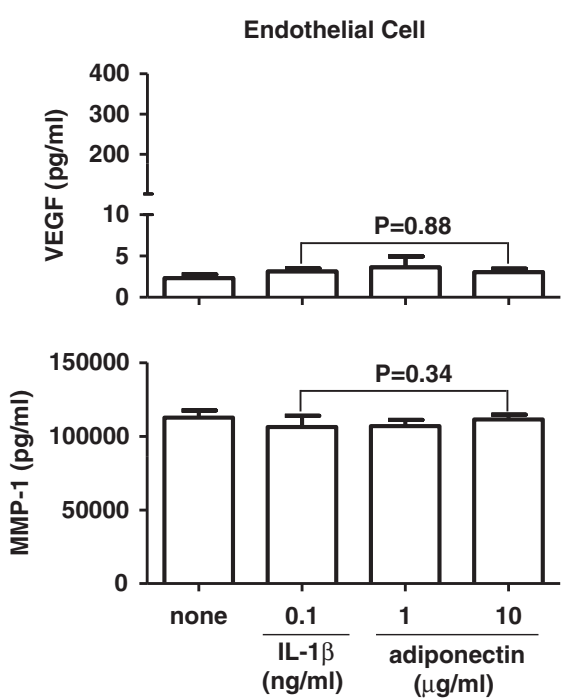

b

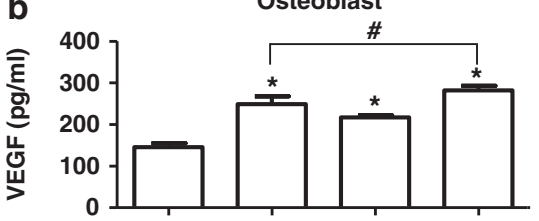

हิ

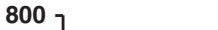

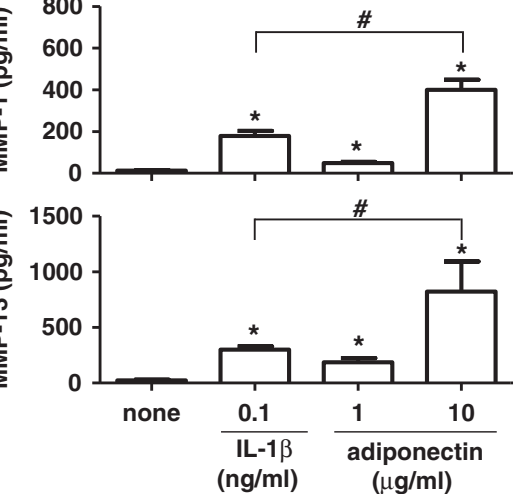

Figure 1 Effect of adiponectin and IL-1 $\beta$ on the production of VEGF, MMP-1 and MMP-13 in (a) endothelial cells and (b) osteoblasts. The cells were treated with adiponectin or IL-1 $\beta$ for $24 \mathrm{~h}$. The culture supernatants were analyzed for VEGF, MMP-1 and MMP-13 by ELISA. The data shown are representative of three independent experiments and similar results were obtained from all three. Values are expressed as mean \pm s.e.m. ${ }^{*} P<0.05$ vs the untreated group, $\# P<0.05$ vs the IL-1 $\beta$-treated group.

IL-1 $\beta\left(0.1 \mathrm{ng} \mathrm{ml}^{-1} ; 281.8 \pm 22.9\right.$ vs $\left.248.8 \pm 18.9 \mathrm{pg} \mathrm{ml}^{-1}\right)$. The MMP-1 expression level was increased by adiponectin in osteoblasts and was significantly greater than that induced by IL-1 $\beta$ stimulation $\left(399.8 \pm 97.5\right.$ vs $\left.178.4 \pm 24.6 \mathrm{pg} \mathrm{ml}^{-1}\right)$. The relative production of MMP-1 in osteoblasts was approximately 1000-fold lower than that in endothelial cells. In contrast, MMP-13 expression was not stimulated by adiponectin in endothelial cells but was significantly increased by adiponectin in osteoblasts. The threefold increase in the MMP13 protein level induced by adiponectin $\left(10 \mu \mathrm{g} \mathrm{ml}^{-1}\right)$ was significantly greater than that induced by IL-1 $\beta\left(0.1 \mathrm{ng} \mathrm{ml}^{-1}\right)$ $\left(821.8 \pm 271.5\right.$ vs $\left.299.5 \pm 58.6 \mathrm{pg} \mathrm{ml}^{-1}\right)$. Considering the physiological concentrations of adiponectin (approximately $1-10 \mu \mathrm{g} \mathrm{ml}^{-1}$ ) and IL-1 $\beta$ (approximately $10-100 \mathrm{pg} \mathrm{ml}^{-1}$ ) in synovial fluid from the arthritic joints of RA patients, adiponectin may be more involved than IL- $1 \beta$ in the induction of VEGF, MMP-1 and MMP-13 protein production in osteoblasts in arthritic joints.

Expression patterns of IL-6 and IL-8 in human endothelial cells and osteoblasts in response to adiponectin

Next, the production levels of IL-6 and IL-8 were also investigated in endothelial cells and osteoblasts stimulated with adiponectin. Adiponectin $\left(10 \mu \mathrm{g} \mathrm{ml}^{-1}\right)$ stimulated the production of IL-6 and IL-8 in both endothelial cells $\left(1552 \pm 409.9 \mathrm{pg} \mathrm{ml}^{-1}\right.$ for IL-6, $28016 \pm 5969 \mathrm{pg} \mathrm{ml}^{-1}$ for IL-8) and osteoblasts $\left(2657 \pm 309.0 \mathrm{pg} \mathrm{ml}^{-1}\right.$ for IL-6, $4586 \pm 292.3 \mathrm{pg} \mathrm{ml}^{-1}$ for IL-8). The adiponectin-stimulated production of IL- 6 and IL- 8 in endothelial cells was approximately 10 -fold higher than that induced by IL-1 $\beta$ $\left(0.1 \mathrm{ng} \mathrm{ml}^{-1}\right) \quad\left(1552 \pm 409.9\right.$ vs $170 \pm 58.2 \mathrm{pg} \mathrm{ml}^{-1}$ for IL-6, and $28016 \pm 5969$ vs $2024 \pm 368.6 \mathrm{pg} \mathrm{ml}^{-1}$ for IL-8) and approximately twofold higher in osteoblasts $(2657 \pm 309.0$ vs $1401 \pm 206.4 \mathrm{pg} \mathrm{ml}^{-1}$ for IL-6, and $4586 \pm 292.3$ vs $1772 \pm 566.7 \mathrm{pg} \mathrm{ml}^{-1}$ for IL-8) (Figure 2). The level of IL-6 in osteoblasts stimulated with adiponectin $\left(10 \mu \mathrm{g} \mathrm{ml}^{-1}\right)$ was similar to that in endothelial cells. However, adiponectinstimulated IL-8 protein production in endothelial cells was approximately sevenfold higher than that in osteoblasts. Considering their physiological concentrations, adiponectin appears to have a more important role than does IL-1 $\beta$ in the induction of IL-6 and IL-8 protein production in endothelial cells. In particular, adiponectin may be involved in the production of IL- 8 in endothelial cells, which may have an important role in the recruitment of neutrophils to arthritic joints.

Effect of hypoxia on the protein expression of IL-6, IL-8, VEGF, MMP-1 and MMP-13 in endothelial cells and osteoblasts in the presence of adiponectin and/or IL-1 $\beta$ Next, we investigated whether adiponectin and IL-1 $\beta$ synergistically stimulate the protein expression of IL-6, IL-8, VEGF and MMPs and whether hypoxia also affects their protein expression in these cells. The protein expression of these factors was investigated in both endothelial cells and osteoblasts stimulated with adiponectin and/or IL-1 $\beta$ in the presence or absence of hypoxia. As shown in Figure 3, VEGF protein production was significantly increased in both endothelial cells and osteoblasts by hypoxia but was not synergistically increased by adiponectin and IL-1 $\beta$. MMP-1 expression in endothelial cells was not significantly affected by hypoxia or by co-treatment with adiponectin and IL-1 $\beta$. In contrast, MMP-1 expression in osteoblasts was additively increased by adiponectin and IL-1 $\beta$; however, the additive 

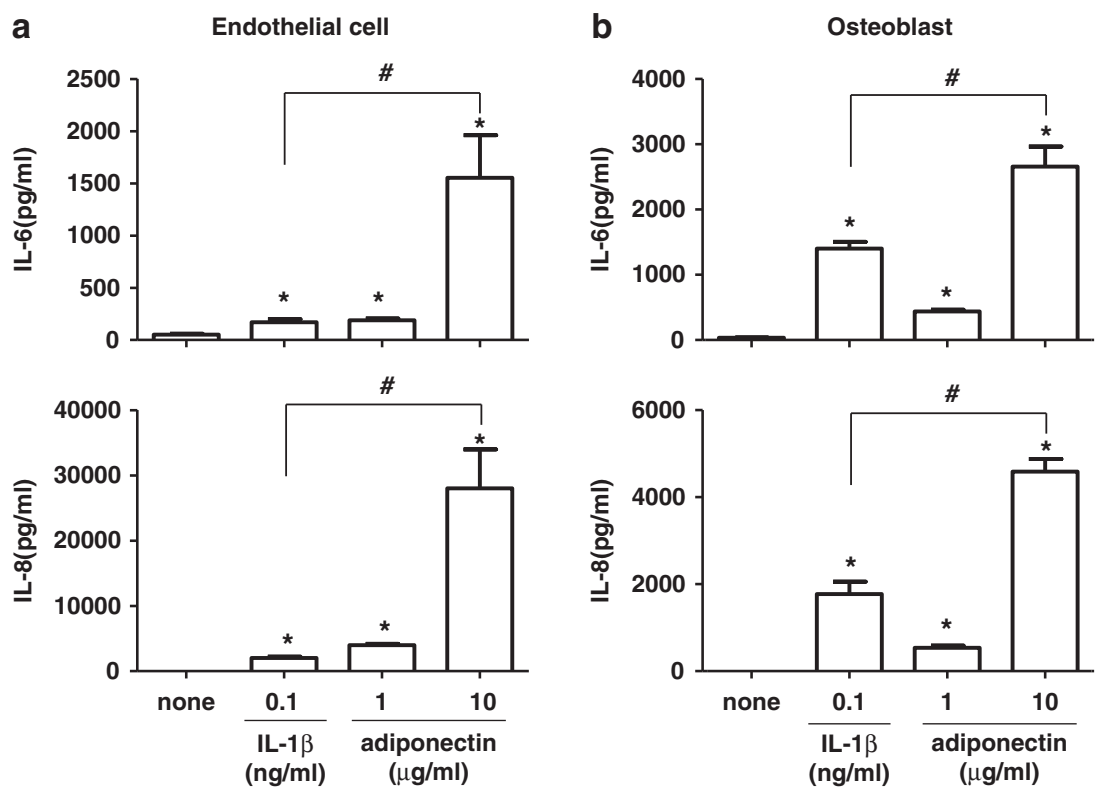

Figure 2 Effects of adiponectin and IL-1 $\beta$ on the production of IL- 6 and IL- 8 in (a) endothelial cells and (b) osteoblasts. The cells were treated with adiponectin or IL-1 $\beta$ for $24 \mathrm{~h}$. The culture supernatants were analyzed for IL- 6 and IL- 8 by ELISA. The data shown are representative of three independent experiments, and similar results were obtained from all three. Values are expressed as mean \pm s.e.m. ${ }^{*} P<0.05$ vs the untreated group, \#P<0.05 vs the IL-1 $\beta$-treated group.

a

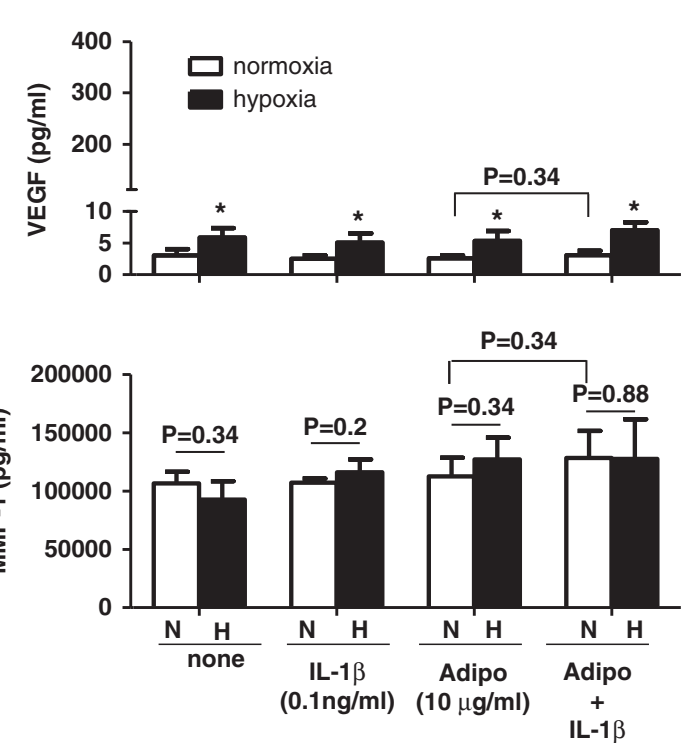

b
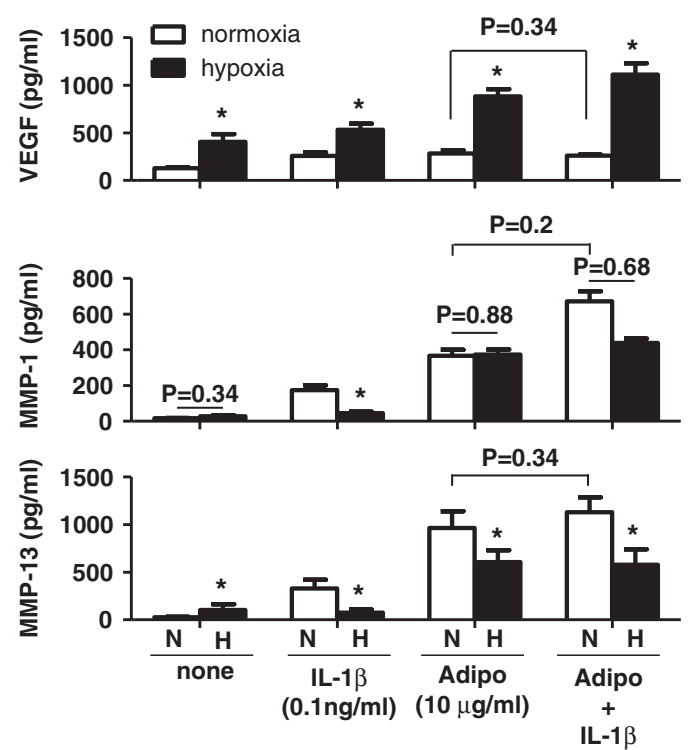

Figure 3 Effect of hypoxia on adiponectin- and IL-1 $\beta$-stimulated production of VEGF, MMP-1 and MMP-13 in (a) endothelial cells and (b) osteoblasts. The cells were treated with adiponectin and/or IL-1 $\beta$ under hypoxic conditions for $24 \mathrm{~h}$. The culture supernatants were analyzed for VEGF, MMP-1 and MMP-13 by ELISA. The data shown are representative of three independent experiments, and similar results were obtained from all the three. Values are expressed as mean \pm s.e.m. ${ }^{*} P<0.05$ vs the normoxia group. $N$, normoxia. $\mathrm{H}$, hypoxia.

increase in MMP-1 expression was significantly decreased under hypoxic conditions. MMP-13 expression in osteoblasts was also additively increased by co-treatment with adiponectin and IL-1 $\beta$; however, the increased expression was decreased by hypoxia. Hypoxia differentially decreased MMP-1 and
MMP-13 expression stimulated by adiponectin or IL-1 $\beta$ according to the type of stimulant (adiponectin or IL-1 $\beta$ ). The expression of IL- 6 and IL-8 in endothelial cells and osteoblasts was not synergistically increased by co-treatment with adiponectin and IL-1 $\beta$ (Figure 4). The increased 
a
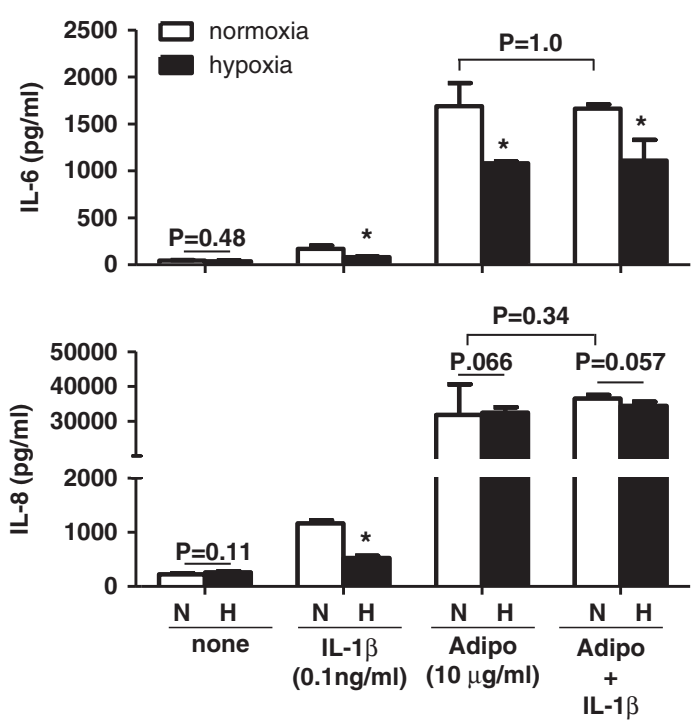

b
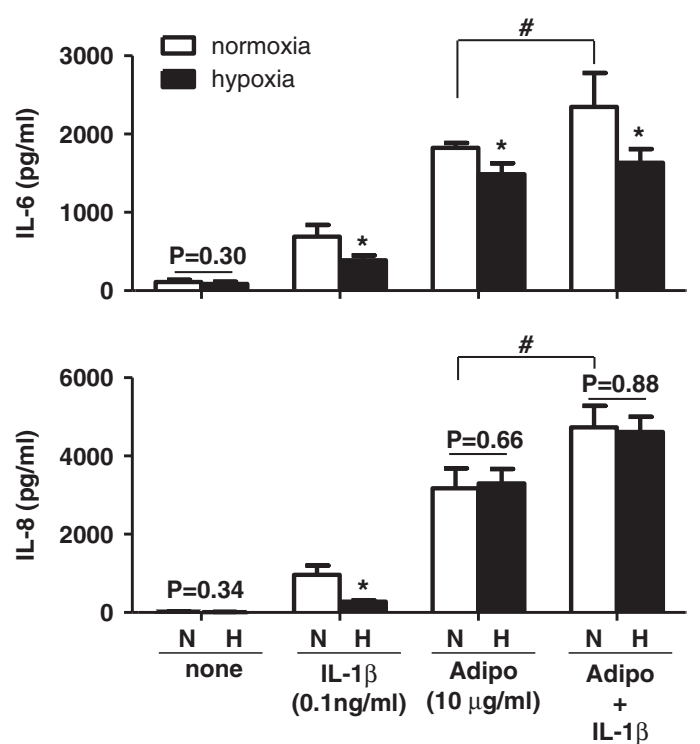

Figure 4 Effects of hypoxia on the adiponectin- and IL-1 $\beta$-stimulated production of IL-6 and IL-8 in (a) endothelial cells and (b) osteoblasts. The cells were treated with adiponectin and/or IL-1 $\beta$ under hypoxic conditions for $24 \mathrm{~h}$. The culture supernatants were analyzed for IL- 6 and IL- 8 by ELISA. The data shown are representative of three independent experiments and similar results were obtained from all three. Values are expressed as mean \pm s.e.m. ${ }^{*} P<0.05$ versus the normoxia group, $\# P<0.05$ versus only the adiponectin-treated group. $\mathrm{N}$, normoxia. $\mathrm{H}$, hypoxia.

expression of IL-6 in osteoblasts was significantly decreased by hypoxia, but IL-8 expression was not affected by hypoxia. These results suggest that adiponectin and IL-1 $\beta$ may additively increase the expression of IL-6, IL-8 and MMP-1 in osteoblasts but not in endothelial cells and that the increase may be differentially regulated by hypoxia.

\section{DISCUSSION}

Recently, adipokines have been shown to exert potent modulatory actions on target tissues and cells involved in rheumatic disease, including cartilage, synovium, bone and various immune cells. ${ }^{23}$ Thus, in previous reports, we studied the effect of adiponectin on the expression of MMPs and proinflammatory mediators such as IL-6 and IL-8 in FLSs. However, there are few reports on the responses of other cell types, such as endothelial cells and osteoblasts, to IL-1 $\beta$ and adiponectin in the presence or absence of hypoxia with respect to the production of MMPs and proinflammatory mediators, although these cells have important roles in the pathogenesis of RA. In this study, we evaluated the contributions of endothelial cells and osteoblasts to the production of VEGF, MMP-1, MMP-13, IL-6 and IL-8 in arthritic joints.

Our previous study showed that adiponectin increased the expression of IL- 6 and IL- 8 in FLSs, although their expression levels were less than those induced by IL-1 $\beta\left(0.1 \mathrm{ng} \mathrm{ml}^{-1}\right)$. In contrast, adiponectin stimulation induced a greater increase in the expression of IL- 6 and IL- 8 in endothelial cells and osteoblasts than did IL- $1 \beta\left(0.1 \mathrm{ng} \mathrm{ml}^{-1}\right)$. This result suggests that adiponectin stimulation of endothelial cells and osteoblasts in arthritic joints may contribute to the production of
IL-6 and IL-8 more than IL-1 $\beta$ stimulation. In addition, adiponectin led to a greater increase in MMP-1 and MMP-13 expression in osteoblasts compared with IL-1 $\beta$ $\left(0.1 \mathrm{ng} \mathrm{ml}^{-1}\right)$. In our previous study, hypoxia differentially regulated the expression of MMP-1 and MMP-13 in IL-1 $\beta$ stimulated FLSs from RA patients. ${ }^{21}$ The increased MMP-1 expression in response to IL-1 $\beta$ stimulation was further stimulated by hypoxic conditions, whereas MMP-13 expression was significantly decreased by hypoxia. However, differential expression of MMP-1 and MMP-13 in FLSs was not detected in osteoblasts. In addition, we previously showed that co-treatment of synoviocytes with IL-1 $\beta$ and adiponectin synergistically increased the expression of IL- 6 and IL- $8,{ }^{24}$ but this effect was not demonstrated in osteoblasts or endothelial cells. These results provide additional evidence to support the hypothesis that adiponectin is involved in the progression and pathogenesis of RA. The underlying mechanisms for the differential responses to adiponectin observed in osteoblasts and endothelial cells and for hypoxia leading to differential MMP-1 and MMP-13 expression in osteoblasts and FLSs under inflammatory stimulation, however, remain unclear. We suspect that the profiles of transcription factors containing HIF- $1 \alpha$ and HIF- $2 \alpha$, which are important in MMP expression, may be differentially activated by adiponectin according to cell type and may thus result in cell-specific MMP expression. In addition, osteoblasts and endothelial cells may not be major producers of inflammatory cytokines and MMPs in arthritic joints. However, their expression level in terms of timing and spatial proximity during the progression of arthritis may be particularly relevant. In particular, MMP expression in 
endothelial cells may be more important than in FLSs to angiogenesis within pannus tissue in terms of spatial proximity.

In general, the most potent isoforms are the high/middle molecular weight isoforms and globular isoforms, whereas the least potent isoform is the adiponectin trimer. ${ }^{25}$ However, another study showed that all isoforms had the same inhibitory effect on the production of ROS in hyperglycemia-stimulated endothelial cells. ${ }^{26}$ Despite the differential effects of adiponectin isoforms, we used a commercial recombinant form of adiponectin produced by E. coli in this study. Thus, our experiments may not replicate in vivo conditions, in which adiponectin stimulates various types of cells in arthritic joints. Nevertheless, the results of our study indicate that the production of IL- 6 and IL-8 in endothelial cells is characteristic of endothelial cells stimulated by proinflammatory cytokines. In support of our results, Frommer et al. showed that adiponectin upregulated the secretion of IL- 6 , IL- 8, GRO $\alpha$, MCP- 1 and RANTES and the mRNA expression of intercellular adhesion molecule 1 and vascular cell adhesion molecule 1 in adiponectin-stimulated human macrovascular endothelial cells. ${ }^{27}$ IL-1 $\beta$ is a more potent inducer of IL- 6 and IL- 8 expression compared with other factors such as tumor necrosis factor-alpha or lipopolysaccharide. ${ }^{28}$ In our study, adiponectin was a more potent inducer of IL- 6 and IL- 8 expression than IL- $1 \beta$ at their physiological concentrations. However, a previous study showed that adiponectin decreased the secretion of IL-8 from human aortic endothelial cells stimulated with tumor necrosis factor-alpha. ${ }^{29}$ In addition, few studies have examined the expression of MMPs in adiponectin-stimulated endothelial cells. In this study, adiponectin did not increase MMP-1 or MMP-13 expression in endothelial cells, but it significantly increased their expression in osteoblasts. A previous study focused on the expression of MMP-2 and MMP-9 in gAdstimulated endothelial cells; ${ }^{25}$ however, we focused on MMP-1 and MMP-13 because they have dominant roles in RA and osteoarthritis and are rate-limiting components in the process of collagen degradation. ${ }^{30,31}$ Additionally, we believe that this effect is due to adiponectin alone, not due to lipopolysaccharide contamination of the recombinant protein produced in an E. coli system, as discussed in previous reports. ${ }^{1,27}$ Thus, adiponectin may have an important role in the destruction of joints by inducing MMP production in osteoblasts in arthritic joints. In our study, adiponectin significantly stimulated increases in MMP-1, MMP-13 and VEGF as well as in IL-6 and IL-8. The increases induced by adiponectin appeared to be higher than those induced by IL$1 \beta$ at their physiological concentrations. This result, to our knowledge, is the first report of adiponectin increasing the expression of these factors in osteoblasts.

This study has some limitations. First, HUVECs were used as the endothelial cells in our experiments. HUVECs may not replicate the endothelial cells found in arthritic joints. However, many studies have shown that HUVECs adequately represent the endothelial cells of arthritic joints. ${ }^{32,33}$ In addition, endothelial cells display IL-6 and IL-8 expression patterns following induction by proinflammatory stimuli that are similar to other endothelial cell types such as human dermal pulmonary microvascular, pulmonary microvascular (HPMVECs), brain (HBECs), pulmonary aortic (HPAECs), coronary artery (HCAECs), and aortic (human aortic endothelial cells) endothelial cells. ${ }^{34-37}$ Thus, despite the limitations of this study, we regarded HUVECs as similar to the type of endothelial cells found within pannus tissue in arthritic joints.

In conclusion, adiponectin appears to have a more important role than does IL- $1 \beta$ in the production of IL- 6 and IL- 8 in endothelial cells at their physiological concentrations. In particular, adiponectin may be involved in the production of IL-8 in endothelial cells, which may have an important role in the recruitment of neutrophils to arthritic joints.

\section{CONFLICT OF INTEREST}

The authors declare no conflict of interest.

\section{ACKNOWLEDGEMENTS}

This research was supported by the Basic Science Research Program through the National Research Foundation of Korea, which is funded by the Ministry of Education, Science and Technology (grant numbers 2010-0024089 and 2011-0009061).

1 Feldmann M, Brennan FM, Maini RN. Rheumatoid arthritis. Cell 1996; 85: 307-310.

2 Mor A, Abramson SB, Pillinger MH. The fibroblast-like synovial cell in rheumatoid arthritis: a key player in inflammation and joint destruction. Clin Immunol 2005; 115: 118-128.

3 Szekanecz Z, Koch AE. Targeting angiogenesis in rheumatoid arthritis. Curr Rheumatol Rev 2008; 4: 298-303.

4 Origuchi T, Migita K, Nakashima T, Tominaga M, Nakamura H, Nakashima M et al. IL-1-mediated expression of membrane type matrix-metalloproteinase in rheumatoid osteoblasts. Clin Exp Rheumatol 2000; 18 333-339.

5 Sakao K, Takahashi KA, Arai Y, Saito M, Honjo K, Hiraoka N et al. Osteoblasts derived from osteophytes produce interleukin-6, interleukin-8 and matrix metalloproteinase-13 in osteoarthritis. J Bone Miner Metab 2009; 27: 412-423.

6 Neumann E, Frommer KW, Vasile M, Muller-Ladner U. Adipocytokines as driving forces in rheumatoid arthritis and related inflammatory diseases? Arthritis Rheum 2011; 63: 1159-1169.

7 Otero M, Lago R, Gomez R, Lago F, Dieguez C, Gomez-Reino JJ et al. Changes in plasma levels of fat-derived hormones adiponectin, leptin, resistin and visfatin in patients with rheumatoid arthritis. Ann Rheum Dis 2006; 65: 1198-1201.

8 Schaffler A, Ehling A, Neumann E, Herfarth H, Tarner I, Scholmerich J et al. Adipocytokines in synovial fluid. JAMA 2003; 290: 1709-1710.

9 Ehling $\mathrm{A}$, Schaffler $\mathrm{A}$, Herfarth $\mathrm{H}$, Tarner $\mathrm{IH}$, Anders S, Distler $\mathrm{O}$ et al. The potential of adiponectin in driving arthritis. J Immunol 2006; 176: 4468-4478.

10 Kitahara K, Kusunoki N, Kakiuchi T, Suguro T, Kawai S. Adiponectin stimulates IL-8 production by rheumatoid synovial fibroblasts. Biochem Biophys Res Commun 2009; 378: 218-223.

11 Choi HM, Lee YA, Lee SH, Hong SJ, Hahm DH, Choi SY et al. Adiponectin may contribute to synovitis and joint destruction in rheumatoid arthritis by stimulating vascular endothelial growth factor, matrix metalloproteinase-1, and matrix metalloproteinase-13 expression in fibroblast-like synoviocytes more than proinflammatory mediators. Arthritis Res Ther 2009; 11: R161.

12 Lago R, Gomez R, Otero M, Lago F, Gallego R, Dieguez C et al. A new player in cartilage homeostasis: adiponectin induces nitric oxide synthase 
type II and pro-inflammatory cytokines in chondrocytes. Osteoarthritis Cartilage 2008; 16: 1101-1109.

13 Gomez R, Scotece M, Conde J, Gomez-Reino JJ, Lago F, Gualillo O. Adiponectin and leptin increase IL-8 production in human chondrocytes. Ann Rheum Dis 2011; 70: 2052-2054.

14 Conde J, Scotece M, Lopez V, Gomez R, Lago F, Pino J et al. Adiponectin and leptin induce VCAM-1 expression in human and murine chondrocytes. PLoS One 2012; 7: e52533.

15 Lee YA, Choi HM, Lee SH, Yang HI, Yoo MC, Hong SJ et al. Synergy between adiponectin and interleukin-1beta on the expression of interleukin-6, interleukin-8 and cyclooxygenase-2 in fibroblast-like synoviocytes. Exp Mol Med 2012; 44: 440-447.

16 Taylor PC, Sivakumar B. Hypoxia and angiogenesis in rheumatoid arthritis. Curr Opin Rheumatol 2005; 17: 293-298.

17 Akhavani MA, Madden L, Buysschaert I, Sivakumar B, Kang N, Paleolog EM. Hypoxia upregulates angiogenesis and synovial cell migration in rheumatoid arthritis. Arthritis Res Ther 2009; 11: R64.

18 Kim KS, Choi HM, Lee YA, Choi IA, Lee SH, Hong SJ et al. Expression levels and association of gelatinases MMP-2 and MMP-9 and collagenases MMP-1 and MMP-13 with VEGF in synovial fluid of patients with arthritis. Rheumatol Int 2011; 31: 543-547.

19 Westra J, Molema G, Kallenberg CG. Hypoxia-inducible factor-1 as regulator of angiogenesis in rheumatoid arthritis-therapeutic implications. Curr Med Chem 2010; 17: 254-263.

20 Dorman G, Cseh S, Hajdu I, Barna L, Konya D, Kupai K et al. Matrix metalloproteinase inhibitors: a critical appraisal of design principles and proposed therapeutic utility. Drugs 2010; 70: 949-964.

21 Lee YA, Choi HM, Lee SH, Hong SJ, Yang HI, Yoo MC et al. Hypoxia differentially affects IL-1 beta-stimulated MMP- 1 and MMP-13 expression of fibroblast-like synoviocytes in an HIF-1alpha-dependent manner. Rheumatology (Oxford) 2012; 51: 443-450.

22 Berner HS, Lyngstadaas SP, Spahr A, Monjo M, Thommesen L, Drevon CA et al. Adiponectin and its receptors are expressed in bone-forming cells. Bone 2004; 35: 842-849.

23 Gomez R, Conde J, Scotece M, Gomez-Reino JJ, Lago F, Gualillo O. What's new in our understanding of the role of adipokines in rheumatic diseases? Nat Rev Rheumatol 2011; 7: 528-536.

24 Lee YA, Choi HM, Lee SH, Yang HI, Yoo MC, Hong SJ et al. Synergy between adiponectin and interleukin-1b on the expression of interleukin-6, interleukin-8 and cyclooxygenase-2 in fibroblast-like synoviocytes. Exp Mol Med 2012; 44: 440-447.

25 Frommer KW, Schaffler A, Buchler C, Steinmeyer J, Rickert M, Rehart S et al. Adiponectin isoforms: a potential therapeutic target in rheumatoid arthritis? Ann Rheum Dis 2012; 71: 1724-1732.

26 Ouedraogo R, Wu X, Xu SQ, Fuchsel L, Motoshima H, Mahadev K et al. Adiponectin suppression of high-glucose-induced reactive oxygen species in vascular endothelial cells: evidence for involvement of a cAMP signaling pathway. Diabetes 2006; 55: 1840-1846.

27 Frommer KW, Zimmermann B, Meier FM, Schroder D, Heil M, Schaffler A et al. Adiponectin-mediated changes in effector cells involved in the pathophysiology of rheumatoid arthritis. Arthritis Rheum 2010; 62: 2886-2899.

28 Mako V, Czucz J, Weiszhar Z, Herczenik E, Matko J, Prohaszka Z et al. Proinflammatory activation pattern of human umbilical vein endothelial cells induced by IL-1beta, TNF-alpha, and LPS. Cytometry A 2010; 77: 962-970.

29 Kobashi C, Urakaze M, Kishida M, Kibayashi E, Kobayashi H, Kihara S et al. Adiponectin inhibits endothelial synthesis of interleukin-8. Circ Res 2005; 97: 1245-1252.

30 Burrage PS, Mix KS, Brinckerhoff CE. Matrix metalloproteinases: role in arthritis. Front Biosci 2006; 11: 529-543.

31 Vincenti MP, Brinckerhoff CE. Transcriptional regulation of collagenase (MMP-1, MMP-13) genes in arthritis: integration of complex signaling pathways for the recruitment of gene-specific transcription factors. Arthritis Res 2002; 4: 157-164.

32 Kayakabe K, Kuroiwa T, Sakurai N, Ikeuchi H, Kadiombo AT, Sakairi T et al. Interleukin-6 promotes destabilized angiogenesis by modulating angiopoietin expression in rheumatoid arthritis. Rheumatology (Oxford) 2012; 51: 1571-1579.

33 Yoon HJ, You S, Yoo SA, Kim NH, Kwon HM, Yoon CH et al. NFAT5 is a critical regulator of inflammatory arthritis. Arthritis Rheum 2011; 63: 1843-1852.

34 Guo W, Wise ML, Collins FW, Meydani M. Avenanthramides, polyphenols from oats, inhibit IL-1 beta-induced NF-kappaB activation in endothelial cells. Free Radic Biol Med 2008; 44: 415-429.

35 Kim KS, Rajagopal V, Gonsalves C, Johnson C, Kalra VK. A novel role of hypoxia-inducible factor in cobalt chloride- and hypoxia-mediated expression of IL-8 chemokine in human endothelial cells. J Immunol 2006; 177: 7211-7224.

36 Franscini N, Bachli EB, Blau N, Leikauf MS, Schaffner A, Schoedon G. Gene expression profiling of inflamed human endothelial cells and influence of activated protein C. Circulation 2004; 110: 2903-2909.

37 Soderquist B, Kallman J, Holmberg H, Vikerfors T, Kihlstrom E. Secretion of IL-6, IL-8 and G-CSF by human endothelial cells in vitro in response to Staphylococcus aureus and staphylococcal exotoxins. APMIS 1998; 106: $1157-1164$.

(c) (1) (9) (2) This work is licensed under a Creative Commons Attribution-NonCommercial-ShareAlike 3.0 Unported License. To view a copy of this license, visit http:// creativecommons.org/licenses/by-nc-sa/3.0/ 